\title{
Effect of Applied Pressure on the Mechanical Properties of 6061 Aluminum Alloy Welded Joints Prepared by Friction Stir Welding
}

\author{
Jawdat A. Al-Jarrah \\ Mechanical Engineering Department \\ Engineering College \\ Northern Border University \\ Arar, Saudi Arabia \\ jawdatj@yahoo.com
}

\author{
Masoud Ibrahim \\ Chemical and Material Science \\ Engineering Dpt, Engineering College, \\ Northern Border University, \\ Arar, Saudi Arabia \\ and Industrial Engineering Dpt, Faculty of \\ Engineering, Fayom University \\ Egypt \\ Ibrahim_64@yahoo.com
}

\author{
Salameh Swalha \\ Mechanical Engineering Dpt, \\ Engineering College \\ Northern Border University \\ Arar, Saudi Arabia \\ and Mechanical Engineering Dpt \\ Faculty of Engineering, Al-Balqa \\ Applied University \\ Jordan \\ sawalhasalameh84@yahoo.com
}

\begin{abstract}
This paper investigates the effect of axial force on the surface appearance and mechanical properties of 6061 aluminum alloy welded joints prepared by friction stir welding. The applied pressure varies from 1.44 to $10.07 \mathrm{MPa}$. The applied pressure was calculated from the axial force which exerted by a spring loaded cell designed for this purpose. Defect free joints obtained at an applied pressure of 3.62 MPa. The mechanical properties of the welded joints were evaluated through microhardness and tensile tests at room temperature. From this investigation, it was found that the joint produced with an applied pressure of $\mathbf{5 . 7 6}$ MPa exhibits superior tensile strength compared to other welded joints. The fracture of this joint happened at the base material.
\end{abstract}

Keywords-friction stir welding; aluminum alloys; applied pressure; mechanical properties

\section{INTRODUCTION}

Since 1930s Aluminum alloys have been the material of choice for aircraft construction. Nowadays 6xxx aluminum used in a variety of applications including aircraft fuselage skins and automobile body panels and bumpers, instead of more expensive $2 \mathrm{xxx}$ and $7 \mathrm{xxx}$ alloys, after appropriate heat treatments [1]. 6xxx alloys have numerous benefits including medium strength, formability, weldability, corrosion resistance, and low cost [2]. Aluminum 6061 is a precipitation hardening alloy containing magnesium and silicon as its major alloying elements [3]. This alloy is highly weldable by Tungsten inert gas welding and by Metal inert gas welding. However, certain welding defects appear, such as solidification cracking porosity, Heat-Affected Zone (HAZ) degradation [4]. Solid state welding techniques such as Friction Stir Welding (FSW) developed by TWI, Cambridge, in 1991 [5] have received great attention in the last years. The process requires lower energy than conventional fusion welding processes [6] and no consumables such as electrodes and protecting gases are needed [7]. FSW has different process parameters that affect the welding process such as tool geometry, axial force, rotational speed, traverses speed and, tool tilt angle as well as base material properties [8-10].

There have been many efforts to understand the effect of process parameters on material flow behavior, microstructure formation and mechanical properties of friction stir welded joints as well as realize their influence on the welding properties [11]. The main two FSW parameters receive interest from researchers are tool rotational speed and welding speed. It is well documented that quality of welded joints increases with increase in tool rotational speed to a maximum value, further increase in tool rotational speed leads to the decrease in quality of welded joints [7]. Welding speed also has a significant effect on joints quality. An increase in welding speed leads to an improvement in mechanical properties up to a maximum limit and further increase result to a decline in mechanical properties. It is well documented that FS welded joints produced under the effect of extrusion process [12], in which the applied axial force and the motion of the tool pin propel the material after it has undergone the plastic deformation. The shoulder force is directly responsible for the plunge depth of the tool pin into the work piece and load characteristics associated with linear friction stir welding [13]. Many research works have demonstrated the effect of axial force in the friction stir welding process which can be concluded in: (a) the material flow in the weld zone during the process and (b) its role in heat input to the welding area. In other word axial force affect the temperature and hydrostatic pressure which is responsible for producing defect free joints [6]. However, the effect of applied pressure on the welding quality of welded joints obtained by FSW is investigated along with other parameters of the FSW 
process. In this paper, the effect of applied pressure on the quality of welded joints produced by FSW is solely investigated. Other FSW parameters like rotational speed, welding speed, shoulder diameter, pin shape and size, were called from an optimal FSW process from previous work [8].

\section{EXPERIMENTAL WORK}

Two rectangular 6061 aluminum alloy plates of $300 \times 150$ $\mathrm{mm}$ size were butt-welded by friction stir welding process and $6 \mathrm{~mm}$ thickness was used. The compositions of base materials used in this investigation are given in Table I. A conventional vertical milling machine was used for the friction stir welding process, by using a fixture. The fixture is tightly fixed on the milling machine table to prevent vibration from occurring as a result of the frictional forces of the welding process. A welding tool with flat shoulder of $24 \mathrm{~mm}$ diameter and $20 \mathrm{~mm}$ height, made of high carbon steel was used. A $6 \mathrm{~mm}$ square pin profile was used to carry out the welding process. A spring-loaded unit was used to change the pressure applied on the shoulder face of the welding tool against the upper surface of the work piece. The calculated pressure values exerted on the shoulder face used in this investigation are 1.44, 3.62, 5.76, 7.92 and 10.07 $\mathrm{MPa}$. The welding process was carried out using a rotational speed of $1000 \mathrm{rpm}$ and a welding (traverse) speed of 1.5 $\mathrm{mm} / \mathrm{sec}$. Single stir pass was applied during the dry welding process. Microstructure examinations were performed using an optical microscope. The specimens, which were taken from the middle of the stirred zone, were prepared by standard metallographic techniques and etched with Keller's reagents to reveal the grain structure. Vickers microhardness was measured with $0.5 \mathrm{kgf}$ load and a dwell period of $10 \mathrm{~s}$. Several measurements were done for each hardness value. In addition, a tensile test on a universal tensile testing machine was carried out to measure the tensile strength of the welded plates, according to ASTM: E8. The tensile test specimens had a gauge diameter of $12 \mathrm{~mm}$ and gauge length of $90 \mathrm{~mm}$.

TABLE I. CHEMICAL COMPOSITION OF THE ALLOY USED (\%WT).

\begin{tabular}{|l|l|l|l|l|l|l|l|l|}
\hline $\mathrm{Si}$ & $\mathrm{Mg}$ & $\mathrm{Cu}$ & $\mathrm{Fe}$ & $\mathrm{Mn}$ & $\mathrm{Ti}$ & $\mathrm{Zn}$ & $\mathrm{Cr}$ & $\mathrm{Al}$ \\
\hline 0.75 & 0.9 & 0.5 & 0.5 & 0.15 & 0.05 & 0.03 & 0.03 & Rest \\
\hline
\end{tabular}

\section{RESULTS AND DISCUSSION}

\section{A. Welding Appearance}

Surface images were collected for the welded pieces under different values of applied pressure. Figure 1 shows the effect of applied pressure on surface appearance of the welds in plates joined by FSW. The rotational speed and welding speed are kept constant at $1000 \mathrm{rpm}$ and $1.5 \mathrm{~mm} / \mathrm{sec}$ respectively. At low pressure, $1.44 \mathrm{MPa}$, the material has poor flow beneath the shoulder face, reducing material loss at retreating side as shown in Figure 1a. Defect free welds were successfully obtained at applied pressure of $3.62 \mathrm{MPa}$, and the plate surface becomes more smoother at $5.76 \mathrm{MPa}$, as shown in Figures $1 \mathrm{~b}$ and 1c respectively. However, at an applied pressure of $7.92 \mathrm{MPa}$, the welding tool would sink to the weld gradually, and a wavy burr starts forming at the edge of the weld region due to the increased heat input to the welding region as shown in Figure 1d. With a further increase of the applied pressure to 10.07 $\mathrm{MPa}$, semicircle streaks appear clearly and more wavy burrs are formed at the weld regions as shown in Figure 1e. A low heat input during the FSW process at a low applied pressure, $1.44 \mathrm{MPa}$, in addition to lack of stirring, reduces the fluidity of aluminum substrate in the stir zone [14].

The microstructure of 6061 aluminum alloy joined by friction stir welding was studied by employing optical microscopy. The microstructure samples are collected from the stir zone. The evolution of the microstructure in the stir zone depends on the recrystallization temperature and the cooling rate of the welding region [15]. The heat input during the welding process controls the temperature in the welding area. The stir zone of the butt-welded plates was cooled by ambient air. The most of the heat generated during friction stir welding arises from the friction at the surface of the tool shoulder, which is proportional to the applied pressure [16]. Figure 2 shows the evolution of the microstructure at the stir zone at different applied pressures. At a low pressure of $1.44 \mathrm{MPa}$, where the induced heat is very small, the microstructure grain of SZ is fine and equiaxed as shown in Figure 2(a). The heat generated during the FSW process depends on the applied pressure on the surface of the welding tool, increasing further in the applied pressure to 3.62 and $5.76 \mathrm{MPa}$ and produces coarsen and deformed grains as shown in Figures $2 \mathrm{~b}$ and $2 \mathrm{c}$. The rate of heat generated during the welding process is directly proportional to the applied pressure. As the heat input increased, the temperature of the stir zone increased, which means relatively prolong heat dissipation. This gives the grains more time to growth [17]. Figure 2d shows that at higher applied pressure of $10.07 \mathrm{MPa}$, the microstructure has elongated grains due to deformation under the surface of welding tools at the same time the grains become more coarsen.

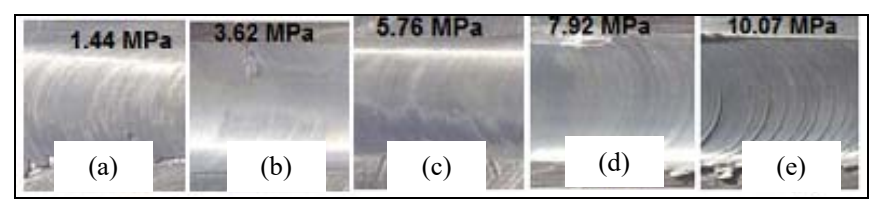

Fig. 1. Appearance of top surface welded at (a) 1.44MPa, (b) $3.62 \mathrm{MPa}$, (c) $5.76 \mathrm{MPa}$, (d) $7.92 \mathrm{MPa}$ and (e) $10.07 \mathrm{MPa}$.
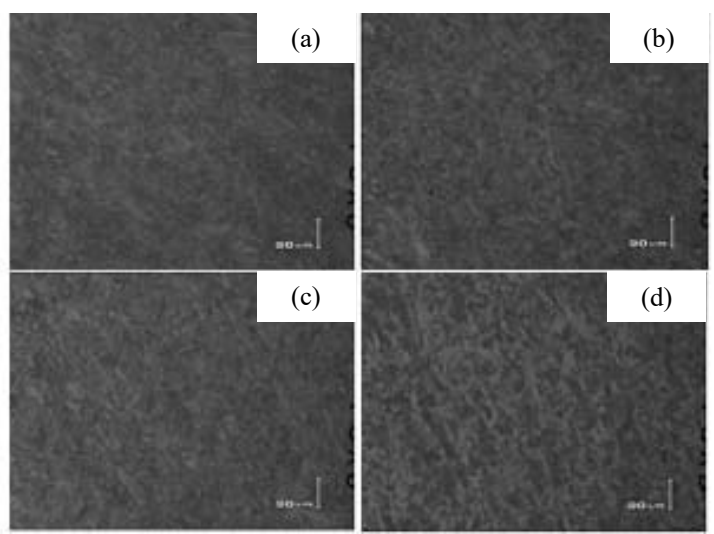

Fig. 2. Microstructure of stir zone at (a) $1.44 \mathrm{MPa}$, (b) $3.62 \mathrm{MPa}$, (c) $5.76 \mathrm{MPa}$ and (d) $10.07 \mathrm{MPa}$ 


\section{B. Mechanical properties}

The microhardness of specimens prepared from all the welded joints at different levels of applied pressure at the welding region are recorded. The average of five readings at the stir zone was taken. The input heat to the welding area during the welding process increases as the applied pressure increased. Figure 3 shows that the microhardness of SZ decreases as the applied pressure increased from 1.44 to 5.76 $\mathrm{MPa}$, and then reduced with a further increase in applied pressure. Figure 4 shows the microhardness profile. The readings were taken from base metal to base metal crossing the SZ under different applied pressure. It has been shown that at low applied pressures there is no significant change in the microhadness in the welding area. However, the microhardness of the stir zone is higher than that of the base metal. This is because the as received parent material was in the homogenized condition wherein all the precipitates are dissolved, thus accounting to a lower hardness due to the absence of strengthening precipitates. In the stir zone, which experiences higher temperatures than the remaining regions, the dissolved precipitates do re-precipitate subsequently. Here the precipitates are finer and uniformly distributed in the stir zone [18].

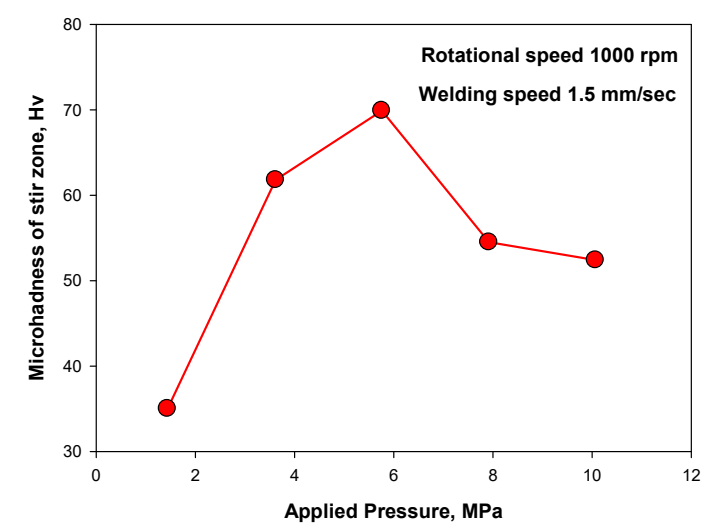

Fig. 3. The variation of microhardness with applied pressure for the stir zone

The tensile properties such as the tensile strength and the elongation of friction stir welded 6061 aluminum alloy joints were evaluated. Under each condition three specimens were tested and the average of the results is recorded. The variety of mechanisms that alter the strength of materials includes work hardening, solid solution strengthening, precipitation hardening, and grain boundary strengthening. In this study, the effect of applied pressure on the strength of aluminum-welded joints was investigated.

Figure 5 reveals the effect of applied pressure on ultimate tensile strength of the welded joints. It has been found that the strength of joint produced with an applied pressure of 5.76 $\mathrm{MPa}$, exhibits a superior strength more than that of the base material as shown in Figure 5. While the other welded joints have a strength lower than that of the base material. The frictional forces between the mating faces (surface of the welding shoulder tool and the welding plates) increased as the applied pressure increases leading to introduce more heat to welding area. The welded joint produced at $5.76 \mathrm{MPa}$, has the highest hardness value as shown in Figure 3, in addition to having a fine grain microstructure [19]. It has been shown that UTS increased as the applied pressure increases up to 5.76 $\mathrm{MPa}$. But at higher applied pressures, excess of heat is introduced to the welding joint, which leads to a decrease on ultimate tensile strength as applied pressure increases to values above 5.76 $\mathrm{MPa}$ [8]. It was reported that GP-zones observed only at low temperature, and assumed that $\beta^{\prime}$ phase is formed directly from the solid solution at temperatures above 100$120^{\circ} \mathrm{C}$ [20]. This precipitate hardening of 6061 aluminum alloy, leads to fabricate welded joints have superior strength more than that of the base material as shown in Figure 6. For the welded joints when the fracture happened outside the welding zone, this joint has more elongation than other joints where the fracture occurred in welding zone as shown in Figure 6. This joint gives the base metal to elongate freely to its own ductility, while other joints fractured before the elongation of the base metal reached.

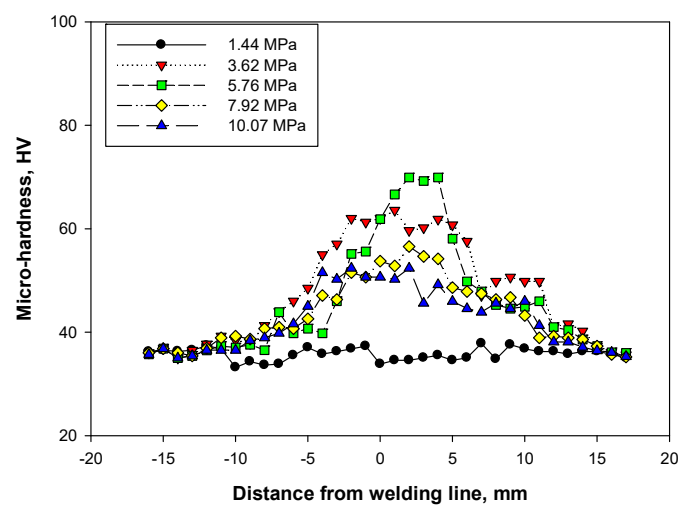

Fig. 4. Hardness profile of FSW joint welded at $1000 \mathrm{rpm}$ and $1.5 \mathrm{~mm} / \mathrm{sec}$

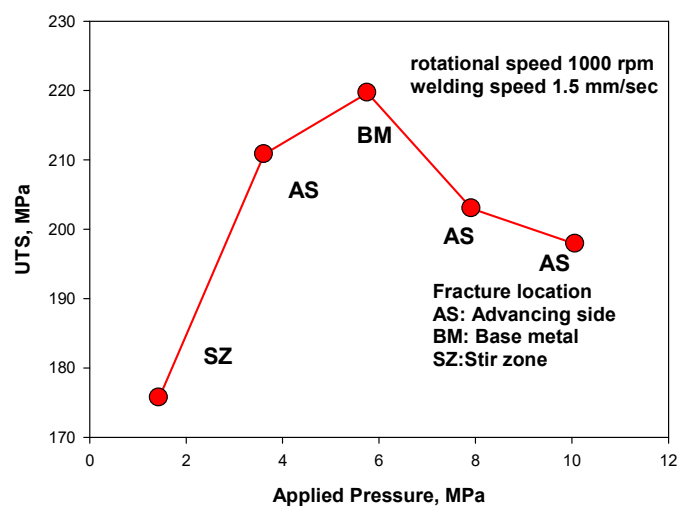

Fig. 5. Variation of ultimate tensile strength with FSW applied pressure

In this investigation, the joints fractured under tension advancing side near the SZ, except the joint prepared at 5.76 $\mathrm{MPa}$ of applied pressure where the fracture occurred at the base metal as shown in Figure 5. This may be due to the difference in microstructure between the SZ and TMAZ. The SZ is 
composed of fine-equiaxed recrystallized grains, while the TMAZ consists of coarse deformed grains. Therefore, the interface between the SZ and TMAZ becomes the poorest location in the tensile test [8].

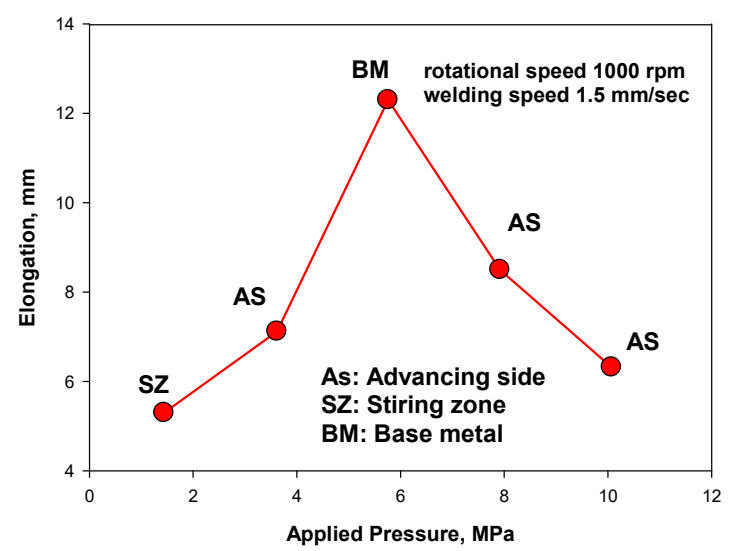

Fig. 6. Elongation of the welded joints prepared at different applied pressures

\section{CONCLUSIONS}

In this study, FSW of 6061 aluminum sheets welded at different applied pressures was investigated. We concluded the following:

- At a low applied pressure of $1.44 \mathrm{MPa}$, the flow of plasticized metal under shoulder face is not sufficient, leading to a loss of metal in the retreating side.

- The microhadness of the SZ increases as the applied pressure increases from 1.44 to $5.76 \mathrm{MPa}$ and then starts decreasing for further increase of pressure.

- The ultimate tensile strength increases to an optimum value then it starts decreasing.

- At an applied pressure of 5.76 MPa, the welded joints have a superior tensile strength compared to the base metal.

- Due to the changes in the microstructure size as moving from ZS to TMAZ, the failure of the test specimens occurred near the welding line in the advanced side.

\section{ACKNOWLEDGMENT}

The authors wish to acknowledge the approval and support of this research study by Grant 434-16 from Deanship of Scientific Research in Northern Border University, Arar, Kingdom of Saudi Arabia.

\section{REFERENCES}

[1] L. P. Troger, E. A Straka, "Microstructural and mechanical characterization of superplastic 6xxx aluminum alloy", Material Science and Engineering, Vol. A277, No.1, pp. 102-113, 2000

[2] T. Evern, B. Ogel, "Influence of heat treatment on the mechanical properties of A6066 alloy", Turkish J. Eng. Env. Sci., Vol. 31, pp. 5360,2007
[3] K. Rohit, K. Ratnesh, R. Singh, A. K. Bajpai, "Mechanical properties of friction stir welded 6061 aluminum alloy", International Journal of Engineering Research \& Technology, Vol. 2, No. 8, pp. 74-80, 2013

[4] Y. M. Zhang, C. Pan, A. T. Male, "Improved microstructure and properties of 6061aluminum alloy weldments using double sided arc welding process", Metallurgical and Material Transaction A, Vol. 31A, No. 10 , pp. $2537-2543,2000$

[5] N. Shanmuga Sundaram, N. Murugan, "Tensile behavior of dissimilar friction stir welded joints of aluminium alloys", Materials and Design, Vol. 31, No. 9, pp. 4184-4193, 2010

[6] G. Elatharasana, V. S. Senthil Kumarb, "An experimental analysis and optimization of process parameter on friction stir welding of AA 6061T6 aluminum alloy using RSM", Procedia Engineering, Vol. 64, pp. 1227-1234, 2013

[7] K. Elangovan, V. Balasubramanian, S. Babu, "Predicting tensile strength of friction stir welded AA6061 aluminium alloy joints by a mathematical model", Materials and Design, Vol. 30, pp.188- 193, 2009

[8] J. A. Al-Jarrah, S. Sawalha, T. A. Abumansour, M. Ibrahim, M. AlRashdan, D. A. Al-Qahsi, "Welding quality and mechanical properties of aluminum joints prepared by friction stir welding", Material and design, Vol. 56, pp. 929-936, 2014

[9] T. Hirata, T. Oguri, H. Hagino, T. Tanaka, S. W. Chung, Y. Takigawa, K. Higashi, "Influence of friction stir welding parameters on grain size and formability in 5083 aluminum alloy", Materials Science and Engineering, Vol. 456, No. 1-2, pp. 344-349, 2007

[10] R. D. By, R. Fu, R. C. Sun, F. C. Zhang, H. J. Liu, "Improvement of formation quality for friction stir welded joints", Welding Journal, Vol. 91, No. 6, pp. 169-173, 2012

[11] S. Rajakumar, C. Muralidharan, V. Balasubramanian, "Influence of friction stir welding process and tool parameters on strength properties of AA7075-T6 aluminum alloy joints", Materials and Design, Vol. 32, pp. 535-549, 2011

[12] S. Rajakumar, C. Muralidharan, V. Balasubramanian, "Establishing empirical relationships to predict grain size and tensile strength of friction stir welded AA 6061-T6 aluminium alloy joints", Trans. Nonferrous Met. Soc. China, Vol. 20, pp. 1863-18722, 2010

[13] M. Jayaraman, R. Sivasubramanian, V. Balasubramanian, "Establishing relationship between the base metal properties and friction stir welding process parameters of cast aluminum alloys", Materials and Design, Vol. 31, pp.4567-4576, 2010

[14] W. B. Lee, Y.M. Yeon, S. B. Jung, "Mechanical properties related to microstructural variation of $6061 \mathrm{Al}$ alloy joints by friction stir welding”, Material Tranactions, Vol. 45, No. 5, pp. 1700-1705, 2004

[15] J. Q. Sua, T. W. Nelson, C. J. Sterling, "Microstructure evolution during FSW/FSP of high strength aluminum alloys", Mater Sci. Eng., Vol. 405, pp. 277-286, 2005

[16] J. J. Muhsin, H. Moneer, Tolepheh, A. M. Muhammad, "Effect of friction stir welding parameters (rotation and transverse) speed the transient temperature distribution in friction stir welding of AA 7020T53", ARPN Journal of Engineering and Applied Sciences, Vol. 7, No. 4, pp. 436-446, 2012

[17] S. Wei, C. Hao, J. Chen, "Study of friction stir welding of 01420 aluminum-lithium alloy", Materials Science and Engineering A, Vol. 453, pp. 170-177, 2007

[18] N. T. Kumbhar, K. Bhanumurthy, "Friction stir welding of Al 6061 alloy", Asian J. Exp. Sci., Vol. 22, pp. 63-74, 2008

[19] A. R. Ros, K. Manisekar, V. Balasubramainan, "Effect of axial force on microstructure and tensile properties of friction stir welded AZ61A magnesium alloy", Trans. Nonferrous Met. So. China, Vol. 21, No. 5, pp. $974-984,2011$

[20] T. V. Christy, N. Murugan, S. Kumar, "A Comparative study on the microstructures and mechanical properties of Al 6061 alloy and the MMC Al 6061/TiB2/12P", J. of Minerals \& Materials Charac. and Eng., Vol. 9, No.1, pp. 57-65, 2010 